\title{
Flow-batch analyser for preparation of calibration standard mixtures in simultaneous multicomponent spectrometric analysis
}

Valeria Visanic, Sara R. R. C. Barros ${ }^{c}$, Heronides A. Dantas Filho ${ }^{b}$ Luciano F. Almeida ${ }^{a}$, Ricardo A. C.

Lima $^{a}$, Wallace D. Fragosoc, Teresa C. B. Saldanha ${ }^{c}$ and Mário C. U. Araújoc*,

${ }^{a}$ Universidade Federal Rural de Pernambuco - UAST - Serra Talhada - PE (Brasil).

${ }^{b}$ Universidade Federal do Pará - Faculdade de Química - Belém - PA (Brasil).

'Universidade Federal da Paraíba - Departamento de Química, Caixa Postal 5093,

58051-970 - João Pessoa - PB (Brasil), Email: laqa@quimica.ufpb.br, fax: +55-83 - 3216.7438.

*Corresponding author

\begin{abstract}
The application of multivariate calibration techniques to multicomponent analysis by UV-VIS molecular absorption spectrometry is a powerful tool for simultaneous determination of several chemical species. However, when this methodology is accomplished manually, it is slow and laborious, consumes high amounts of reagents and samples, is susceptible to contaminations and presents a high operational cost. To overcome these drawbacks, a flow-batch analyser is proposed in this work. This analyser was developed for automatic preparation of standard calibration and test (or validation) mixtures. It was applied to the simultaneous determination of $\mathrm{Cu}^{2+}, \mathrm{Mn}^{2+}$ and $\mathrm{Zn}^{2+}$ in polyvitaminic and polymineral pharmaceutical formulations, using 4-(2-piridilazo) resorcinol as reagent and a UV-VIS spectrophotometer with a photodiode array detector. The results obtained with the proposed system are in good agreement with those obtained by flame atomic absorption spectrometry, which was employed as reference method. With the proposed analyser, the preparation of calibration and test mixtures can be accomplished about four hours, while the manual procedure requires at least two days. Moreover, it consumes smaller amounts of reagents and samples than the manual procedure. After the preparation of calibration and test mixtures, 60 samples $\mathrm{h}^{-1}$ can be carried out with the proposed flow-batch analyser.
\end{abstract}

Keywords: Flow-batch analyser, preparation of standard mixtures, simultaneous multicomponent analysis, UV-VIS spectrophotometry, drug analysis. 


\section{Introduction}

Nowadays, several techniques for simultaneous determination of chemical species exist, such as X-Ray Fluorescence Spectrometry (XRFS) [1, 2], Atomic and Molecular Fluorescence Spectrometry (AFS and MFS) [3, 4], Chromatography [5], Atomic Emission Spectrometry (AES), among others [6]. These techniques are relatively expensive in acquisition and maintenance, turning them less accessible to the most of the industrial and research laboratories. The UV-VIS Molecular Absorption Spectrometry (UV-VIS-MAS) [7] is an analytical method broadly used, due to its simplicity and fast achievement of experimental results. It is classically accomplished, by using chromogenic reagents.

However, the simultaneous determination using UV-VIS-MAS is frequently hindered because it supplies overlapped spectra with hard interpretation for quantitative determinations. To solve the overlapping problem the analyte of interest can be separated from the matrix or the interfering species can be masked by adding suitable reagents. Alternatively a specific reagent for each analyte can be used.

4-(2-piridylazo) resorcinol (PAR) is an important reagent of the nitrocompounds group, widely used as spectrometric reagent [8-10]. The main PAR advantage over other reagents is that their metallic compounds are soluble in water, simplifying the analytical procedure and avoiding subsequent stages of extraction with organic solvents. Besides, PAR reacts with several metals yielding colored chelates which present high absorption in the ultraviolet-visible region of the spectrum. Their large molar absorptivities allied with their wide bands results in overlapping of the complexes spectra. Usually, this drawback may be overcome by the selection of the wavelength and by suitable choice of the molar ratio PAR to metals.

Though in practice, the separation of interfering species may be difficult and slow. The chemometric methods have been used to solve problems related to multicomponent analysis. The multivariate calibration methods as Multiple Linear Regression (MLR) Principal Components
Regression (PCR) and Regression for Partial Least Squares (PLS) are frequently used to quantitative analysis. The association of the chemometric techniques with methods based on UV-VIS-MAS has been applied successfully in the simultaneous determination of two or more species. However, the manual accomplishment of these techniques requires the preparation of a large number of mixtures (calibration and tests sets), which implies in higher amounts of reagents and samples and in the decreasing of the analytical frequency. The development of automatic systems has proved to be a good alternative way to circumvent these problems. Versatile and flexible flow-batch approaches (FBA) have been proposed to automate several analytical systems [28-37] and have been named and developed by our research group. As most of the flow analysers, FBA also present significant precision and accuracy, high sample throughput and low contamination, low consumption and manipulation of reagents and samples, low cost per analysis and low waste volumes.

In this work, a FBA system is proposed in which the calibration and the sample solutions can be treated in order to carry out simultaneous and multicomponent analysis (FBA-SMA) by UVVIS-MAS and PLS. The versatility and flexibility inherent to FBA provides the possibility to yield the calibration and test mixtures accurately and quickly. Hence, it allows performing multivariate calibration techniques with low consume of reagents and samples, high sample throughput, low cost per analysis. The FBA-SMA was applied to analysis of commercial samples of polyvitaminic and polymineral pharmaceutical formulations, available in Brazil.

\section{EXPERIMENTAL}

\section{Reagents, Samples and Solutions}

PAR solution: a $1.62 \times 10^{-3} \mathrm{~mol} \mathrm{~L}^{-1}$ PAR solution was prepared in $0.05 \mathrm{~mol} \mathrm{~L}^{-1} \mathrm{NH}_{3}$ by dissolving $0.2067 \mathrm{~g}$ of $\mathrm{C}_{11} \mathrm{H}_{8} \mathrm{~N}_{3} \mathrm{NaO}_{2} \cdot \mathrm{H}_{2} \mathrm{O}$ (Merck) in deionized water, adding $0.583 \mathrm{~mL}$ of $25 \% \mathrm{NH}_{4} \mathrm{OH}$ and diluting to $500.0 \mathrm{~mL}$. 
Borate buffer (pH 9.0): a $0.01 \mathrm{~mol} \mathrm{~L}^{-1}$ borax solution was prepared by dissolving $\mathrm{Na}_{2} \mathrm{~B}_{4} \mathrm{O}_{7} \cdot 10 \mathrm{H}_{2} \mathrm{O}$ in deionized water.

The $1.000 \mathrm{mg} \mathrm{L}^{-1} \mathrm{Cu}^{2+}, \mathrm{Mn}^{2+}$ and $\mathrm{Zn}^{2+}$ stock solutions were prepared from Titrisol (Merck) ampoules in $0.01 \% \mathrm{HCl}(\mathrm{v} / \mathrm{v})$ for $\mathrm{Cu}^{2+}$ and $0,04 \%$ $(\mathrm{v} / \mathrm{v})$ for $\mathrm{Mn}^{2+}$ and $\mathrm{Zn}^{2+}$.

Commercial samples of polyvitaminic and polymineral pharmaceutical formulations were used. Each tablet with approximately 4.700 g contains $\mathrm{Cu}^{2+}, \mathrm{Mn}^{2+}$ and $\mathrm{Zn}^{2+}$ in concentrations specified by the manufacturer: $0.4 \mathrm{mg}, 0.5 \mathrm{mg}$ and $3.0 \mathrm{mg}$, respectively. Each effervescent tablet was weighed and dissolved in deionized water. After a suitable time (about 15 minutes), enough to eliminate all the $\mathrm{CO}_{2}$ present, the volume was completed up to $250.0 \mathrm{~mL}$.

The reference method used for comparison purposes was the flame atomic absorption spectrometry (FAAS). Standard solutions were prepared as described above. In the $\mathrm{Zn}^{2+}$ determination, a further dilution was required, taking an aliquot of
$4.0 \mathrm{~mL}$ of the sample and completing the volume up to $50.0 \mathrm{~mL}$.

A $9.78 \times 10^{-5}$ mol $\mathrm{L}^{-1}$ methyl orange $\left[\left(\mathrm{CH}_{3}\right)_{2} \mathrm{NC}_{6} \mathrm{H}_{4} \mathrm{~N}: \mathrm{N}^{-\mathrm{C}_{6}} \mathrm{H}_{4} \mathrm{SO}_{3} \mathrm{Na}\right]$ (Merck) was used as dye solution in the measurement of volumetric ratios [38] procedure.

A solution containing the buffer and the PAR in the same proportions of the mixtures was used in blank measurements.

All solutions were prepared with chemicals of analytical grade. Freshly distilled and deionised water in a system Milli-Q Plus (MILLIPORE) was used.

\section{The Automatic Analyser}

The FBA-SMA system is shown in figure 1. A Hewllet Packard model HP 8453 UV-VIS spectrophotometer was employed as detector. The reference method was applied using a GBC 908AA flame atomic absorption spectrometer.

Figure 1. Schematic diagram of FBA-SMA. D: Detector; V1-V7: Solenoid valves; S: Sample; MC: Mixing chamber; MS: Magnetic stirrer; M1-M3: Standard solutions of the analytes; B: Buffer; R: PAR reagent and W: Water.

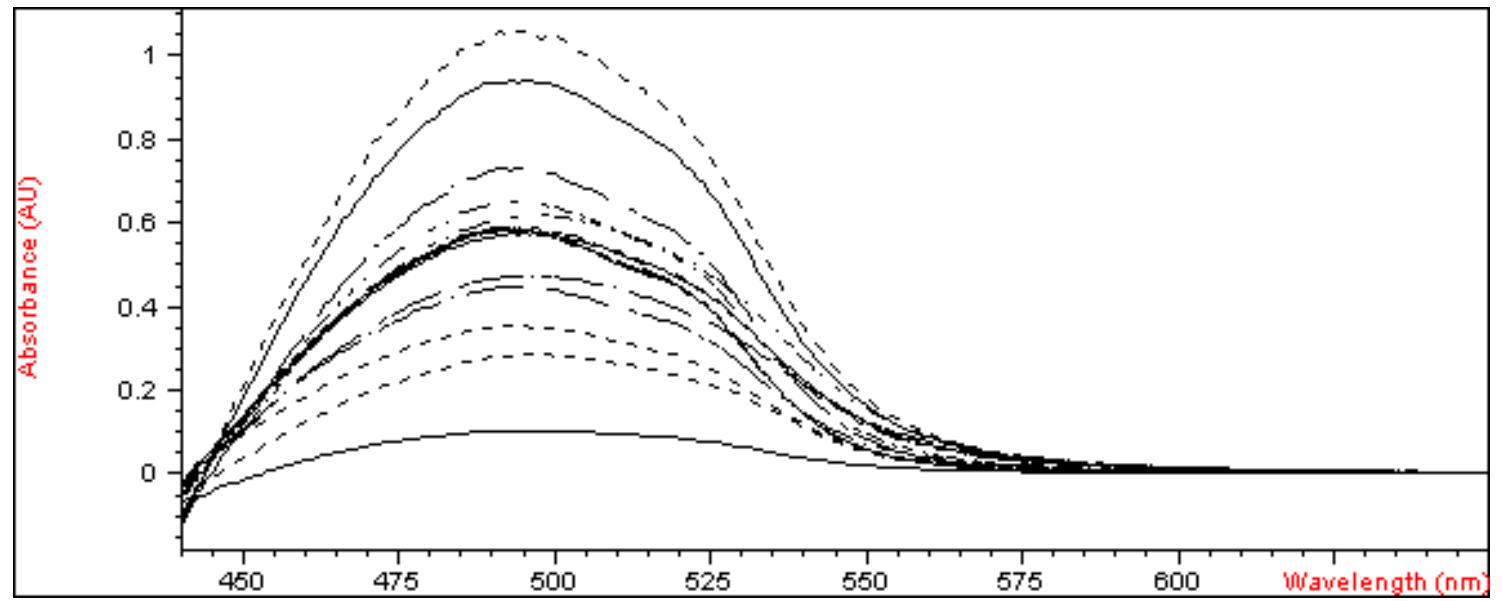

A Gilson Miniplus 3 peristaltic pump and 1.85 mm i.d. Tygon ${ }^{\circledR}$ pumping tubes were used. The transmission lines were constructed with $0.8 \mathrm{~mm}$ i.d. Teflon ${ }^{\circledR}$ tubing. A $2.0 \mathrm{~mL}$ laboratory-made mixing chamber was constructed in Teflon ${ }^{\circledR}$. A Hellma quartz flow cell with $10 \mathrm{~mm}$ optic path was used. Seven Cole-Parmer three-way solenoid valves were used: three valves $\left(V_{1}, V_{2}\right.$ and $\left.V_{3}\right)$ were used to direct the standard solutions of the ion metals into mixing chambers (MC); three valves $\left(\mathrm{V}_{4}, \mathrm{~V}_{5}\right.$ and $\left.\mathrm{V}_{6}\right)$ were used 
to direct buffer, sample and PAR solution respectively and seventh valve $\left(\mathrm{V}_{7}\right)$ was used to select the stream flowing (water or MC mixture) towards flow-cell of the spectrophotometer. Details of MC can be found elsewhere [28].

A Pentium $233 \mathrm{MHz}$ microcomputer equipped with a laboratory-made parallel interface card was used to control the proposed system. The control of the system was performed by a program developed in Labview ${ }^{\circledR}$ 5.1, which also controls the spectrometer hardware. An electronic actuator (EA) increased the power of the signal sent by the microcomputer in order to control the magnetic stirrer and the valves.

\section{Procedure}

The analytical procedure is based on the insertion of time controlled volumes of the standard solutions of the ion metals, buffer, PAR and samples solutions towards MC, following homogenization and the transport of the resulting mixture towards detector. The solenoid valves switching on time intervals previously selected by the analyst are proportional to the volume inserted into MC of each solution. Before starting the procedure, the solution in each channel is pumped and recycled towards its flasks, with all the valves initially switched off.

The MC cleaning step is always accomplished before any measurement. It is carried out switching on the valves $\mathrm{V}_{4}$ (buffer $\mathrm{pH} 9.0$ ) and $\mathrm{V}_{6}$ (PAR reagent) during the same time interval, producing the blank solution (buffer + PAR reagent). Afterwards, this mixture is homogenized during enough time to accomplish the MC cleaning. The valve $\mathrm{V}_{7}$ is switched on, allowing the MC emptying and discarding the cleaning mixture. The blank solution is introduced in the system as described in the cleaning step. In this case however the spectrum is obtained and registered.

To carry out the step of preparation of the calibration and test mixtures, the standard solutions valves $\left(\mathrm{V}_{1}, \mathrm{~V}_{2}\right.$ and $\left.\mathrm{V}_{3}\right)$ and buffer valve $\left(\mathrm{V}_{4}\right)$ are switched on during predefined time intervals and the resulting solution is homogenized for a suitable time. So, the PAR valve $\left(\mathrm{V}_{6}\right)$ is switched on during a predefined time, yielding the mixture (buffer + metals + PAR). Afterwards, this mixture is homogenized in order to reach a complete re- action and afterwards it is pumped towards flow cell of the spectrophotometer, where its spectrum is measured and registered. This procedure is repeated for all calibration and test mixtures. In the sample measurement step, only the valves $V_{4}, V_{5}$ and $\mathrm{V}_{6}$ are used and the same procedure used for calibration and test is applied.

\section{Procedure of Measurement of Volumetric Ratios}

The concentrations of the metallic species into MC depend on the switching time of the solenoids valves. This time is proportional to the volume inserted into MC and it varies according to the flow-rate used in each channel, thus, these flow-rates should be well known in order to obtain concentrations with accuracy. If the flow-rates were maintained constant, the total volume into MC should be also constant; however, it doesn't happen in practice. It occurs due to the asymmetry existent among the pumping channels, furnishing little differences in each channel flow-rate. As consequence, variations in the switching times will implicate in variations of the total volume of the mixture into MC, resulting a systematic error in the analysis and consequently inaccuracy in the determinations. To solve this problem, a correction in the switching time of the valves must be performed. This correction is accomplished in agreement with the procedure described below.

Considering two solenoid valves, one is regarding the channel of a given ion metal $\mathbf{M}$, and other to the sample channel S. If the flow-rates and switching times of these valves are the same, then:

$V_{M}=V_{S}$

where $\mathrm{V}_{\mathrm{M}}$ and $\mathrm{V}_{\mathrm{S}}$ is the volume of the metal and of the sample, respectively. Since $\mathrm{Q}=\mathrm{V} / \mathrm{t}$, (where $\mathrm{Q}$ is the flow rate), the valve timing, $\mathrm{t}$, defines the volumes, $\mathrm{V}$, inserted into $\mathrm{MC}$, then, the Eq. (1) can be written as:

$$
Q_{M} t_{M}=Q_{S} t_{S}
$$


where $\mathrm{Q}_{\mathrm{M}}, \mathrm{t}_{\mathrm{M}}, \mathrm{Q}_{\mathrm{S}}$ and $\mathrm{t}_{\mathrm{s}}$ are the flow-rates and switching times of the metal and sample channels, respectively. Making the sample valve as reference valve, Eq. 2 can be rewrite as:

$t_{M}=t_{S} \frac{Q_{S}}{Q_{M}}$

In this way, the switching time of the metal valve, $t_{\mathrm{M}}$, will be corrected according to the ratio of the channels flow-rates, always taking as reference the sample channel. To determinate this ratio, initially, a dye solution is pumped during a given time, $\mathrm{t}$, through the sample channel and the buffer through the metal channel.

Methyl orange was used as dye. After homogenization, the mixture is pumped towards the detector, obtaining the signal $\mathrm{A}_{1}$. Afterwards, the positions of the solutions are inverted and these solutions are pumped during the same interval of time, t, obtaining the signal $\mathrm{A}_{2}$. If a linear relationship between absorbance and concentration of the dye solution is observed, the ratio $R_{v}$ between $\mathrm{Q}_{\mathrm{s}}$ and $\mathrm{Q}_{\mathrm{m}}$ may be given by Eq 4:

$$
R_{V}=\frac{Q_{S}}{Q_{M}}=\frac{A_{2}}{A_{1}}
$$

This equation can be deduced starting from the following considerations:

The flow-rates $\mathrm{Q}_{\mathrm{S}}$ and $\mathrm{Q}_{\mathrm{M}}$ are given by:

$$
Q_{S}=\frac{V_{S}}{t}
$$

$Q_{M}=\frac{V_{M}}{t}$

The signals $A_{1}$ and $A_{2}$ are defined by:

$$
A_{2}=\frac{V_{M}}{V_{t o t}} A_{a b s}
$$

$$
A_{2}=\frac{V_{S}}{V_{t o t}} A_{a b s}
$$

where $\mathrm{V}_{\text {tot }}$ is the total volume, the sum of the volumes of dye and buffer solutions. $A_{a b s}$ is the signal obtained for the pure dye solution.

From Eq. (5) and (6), is found that:

$$
\frac{Q_{S}}{Q_{M}}=\frac{V_{S} / t}{V_{M} / t}=\frac{V_{S}}{V_{M}}
$$

Isolating the variables $\mathrm{V}_{\mathrm{S}}$ and $\mathrm{V}_{\mathrm{M}}$ in the Eq. (7) and (8) and substituting in Eq. (9), the Eq. (10) is obtained:

$$
\frac{Q_{S}}{Q_{M}}=\frac{A_{2} V_{t o t}}{A_{a b s}} / \frac{A_{1} V_{t o t}}{A_{a b s}} \Rightarrow \frac{Q_{S}}{Q_{M}}=\frac{A_{2}}{A_{1}}
$$

which is similar to Eq. (4).

These measurements should be carried out only sporadically, especially when the pumping tubes are exchange.

\section{Calibration}

To construct the calibration models relative to the matrixes $\mathrm{X}$ (spectra) and Y (concentrations of the elements) the partial least squares regression (PLS) method was used). In PLS models, the absorbances values corresponding to each wavelength were the independent variables and the concentrations of the metals in the mixtures sets were the dependent variables. The validation compares the results obtained for the model with the respective values considered true. The calculations were accomplished by using the program UNSCRAMBLER, version 6.1 [39]. The model construction was performed in three stages; the planning of the calibration and test mixtures used for calibration and validation of the model; spectra acquisition from these mixtures and of the samples and calibration and validation of the employed models. 


\section{Calibration Mixtures}

To define the concentrations of the elements in the calibration mixtures a complete $2^{3}$ factorial design was used. In the calibration set, five authentic replicates of a randomly chosen mixture were included in the original set (Table 1).

Table 1. Mixture calibration set and respective metals concentration (mg L-1)

\begin{tabular}{cccc}
\hline Calibration Mixtures & $\mathrm{Cu}^{2+}$ & $\mathrm{Mn}^{2+}$ & $\mathrm{Zn}^{2+}$ \\
\hline CM1 & 0.05 & 0.03 & 0.05 \\
CM2 & 0.45 & 0.03 & 0.05 \\
CM3 & 0.05 & 0.25 & 0.05 \\
CM4 & 0.45 & 0.25 & 0.05 \\
CM5 & 0.05 & 0.03 & 0.45 \\
CM6 & 0.45 & 0.03 & 0.45 \\
CM7 & 0.05 & 0.25 & 0.45 \\
CM8 & 0.45 & 0.25 & 0.45 \\
CM5.1 & 0.05 & 0.03 & 0.45 \\
CM5.2 & 0.05 & 0.03 & 0.45 \\
CM5.3 & 0.05 & 0.03 & 0.45 \\
CM5.4 & 0.05 & 0.03 & 0.45 \\
CM5.5 & 0.05 & & 0.45 \\
\hline
\end{tabular}

The concentration linear ranges established for these ion metals in the visible region were found previously by Saldanha et al. [40] and were used in this work. The concentrations of each metal are converted in switching on time of the valves and their values are corrected in agreement with the respective channels flow-rates. This correction is based on the measure of the volumetric ratios (see Section 2.3.1). Table 2 presents switching on times of the solenoid valves needed to obtain the metal concentrations presented in Table 1. 
Table 2. Calibration mixtures valve timings (s).

\begin{tabular}{cccc}
\hline Calibration Mixtures & $\mathrm{Cu}^{2+}$ & $\mathrm{Mn}^{2+}$ & $\mathrm{Zn}^{2+}$ \\
\hline CM1 & 1.03 & 1.02 & 1.10 \\
CM2 & 9.27 & 1.02 & 1.10 \\
CM3 & 1.03 & 8.48 & 1.10 \\
CM4 & 9.27 & 8.48 & 1.10 \\
CM5 & 1.03 & 1.02 & 9.86 \\
CM6 & 9.27 & 1.02 & 9.86 \\
CM7 & 1.03 & 8.48 & 9.86 \\
CM8 & 9.27 & 8.48 & 9.86 \\
CM5.1 & 1.03 & 1.02 & 9.86 \\
CM5.2 & 1.03 & 1.02 & 9.86 \\
CM5.3 & 1.03 & 1.02 & 9.86 \\
CM5.4 & 1.03 & 1.02 & 9.86 \\
CM5.5 & 1.03 & 1.02 & 9.86 \\
\hline
\end{tabular}

\section{Test Mixtures}

The test mixtures set used for validation of the model were built according to the procedure used by Saldanha et al. [40] within the concentration range of the calibration set. The five resulting combinations to be used are shown in Table 3 .

Table 3. Metal concentrations in the test mixtures set $\left(\mathrm{mg} \mathrm{L}^{-1}\right)$.

\begin{tabular}{clll}
\hline Test Mixtures & $\mathrm{Cu}^{2+}$ & $\mathrm{Mn}^{2+}$ & $\mathrm{Zn}^{2+}$ \\
\hline MT1 & 0.16 & 0.18 & 0.34 \\
MT2 & 0.34 & 0.06 & 0.22 \\
MT3 & 0.34 & 0.15 & 0.16 \\
MT4 & 0.16 & 0.09 & 0.22 \\
MT5 & 0.11 & 0.12 & 0.16 \\
\hline
\end{tabular}


Table 4 presents the corrected valve timings for the mixture test set.

Table 4. Metal valve timings in the test mixtures set (s).

\begin{tabular}{cccc}
\hline Test Mixtures & $\mathrm{Cu}^{2+}$ & $\mathrm{Mn}^{2+}$ & $\mathrm{Zn}^{2+}$ \\
\hline TM1 & 3.30 & 6.11 & 7.45 \\
TM2 & 7.00 & 2.04 & 4.82 \\
TM3 & 7.00 & 5.09 & 3.51 \\
TM4 & 3.30 & 3.05 & 4.82 \\
TM5 & 2.27 & 4.07 & 3.51 \\
\hline
\end{tabular}

\section{RESULTS AND DISCUSSION}

The FBA-SMA was applied to the determination of $\mathrm{Cu}^{2+}, \mathrm{Mn}^{2+}$ and $\mathrm{Zn}^{2+}$ in polyminerals and polivitaminic drugs in a pre-selected spectral range [40], from 470 to $530 \mathrm{~nm}$. To compare the results obtained by FBA-SMA with those obtained by the FAAS method, it was assumed that the determined metals were present in the samples as sulphates $\left(\mathrm{MSO}_{4} \cdot \mathrm{nH}_{2} \mathrm{O}\right)$, which is more stable [41] according to the vademecum of the drugs.

Starting from the spectra data and using the matrix of calibration, a PLS model was built to predict the concentrations of the metals. Figures 2 to 4 show spectra of the calibration mixtures, test mixtures and actual samples.

Figure 2. Absorption Spectra of the calibration and test mixtures in a range from 440 to $700 \mathrm{~nm}$.

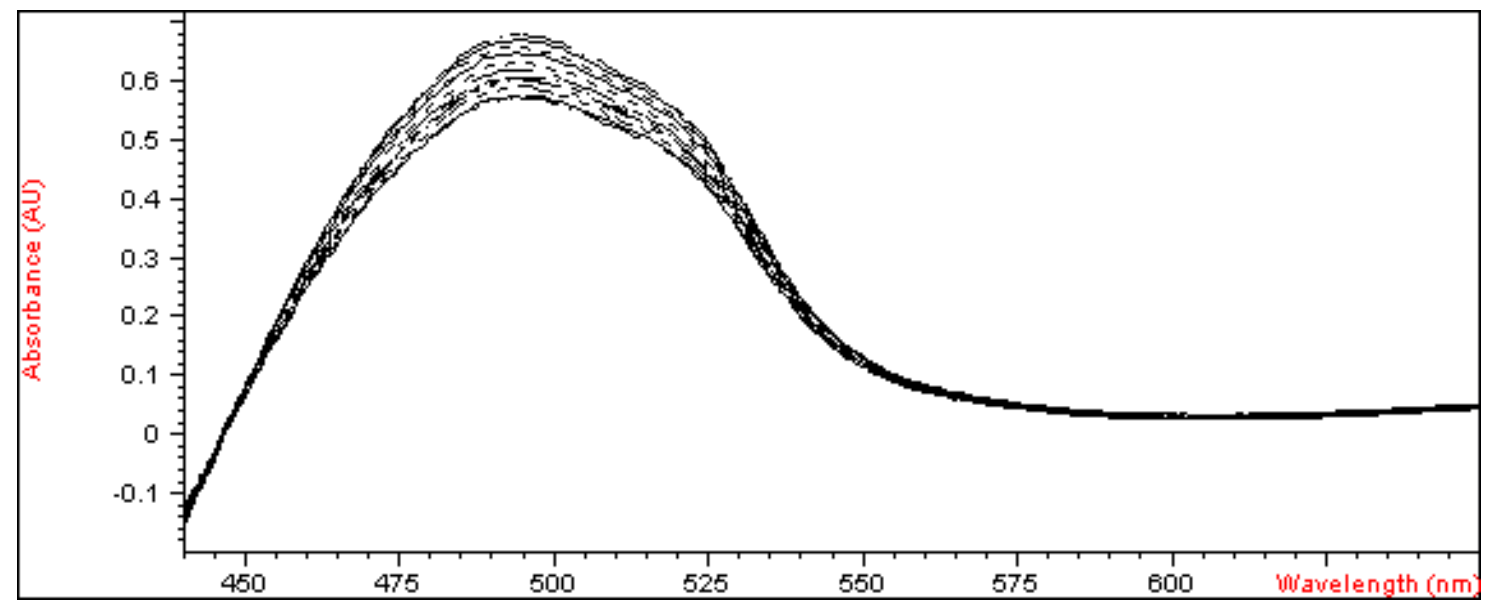


Figure 3. Absorption Spectra of the actual samples in the spectral band from 440 to $700 \mathrm{~nm}$.

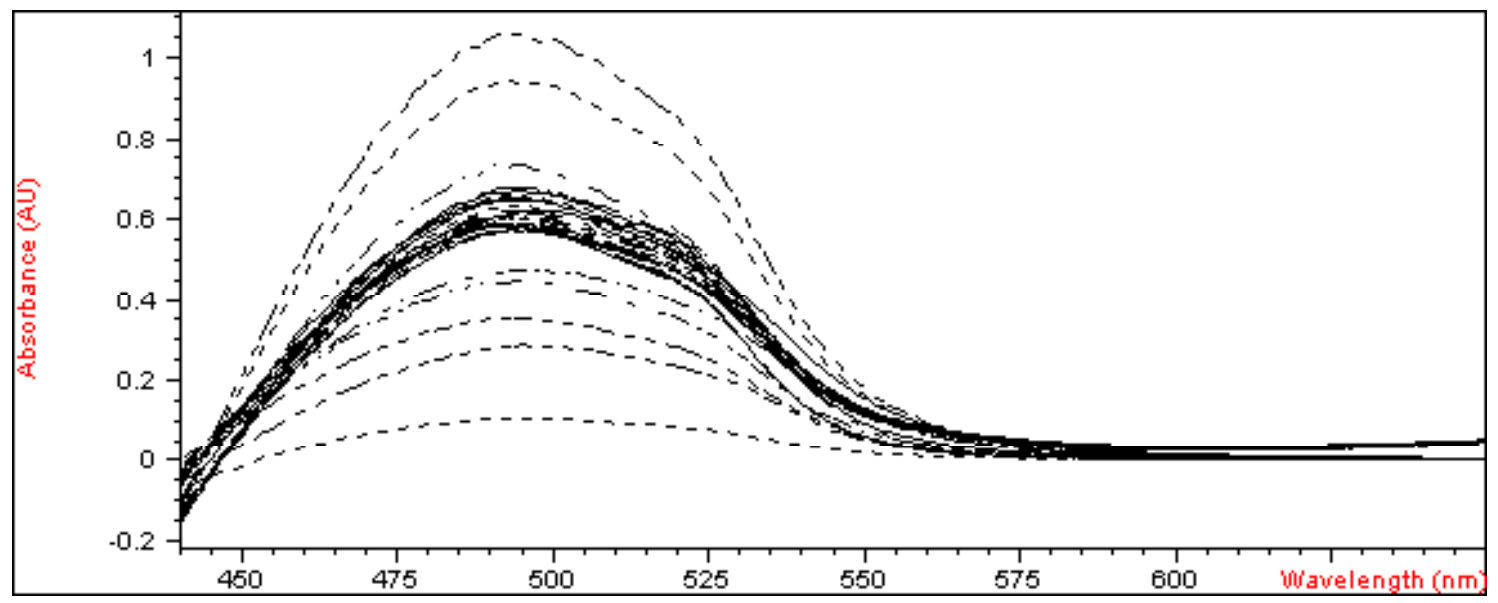

Figure 4. Overlapping of all spectra from 440 to $700 \mathrm{~nm}$ band

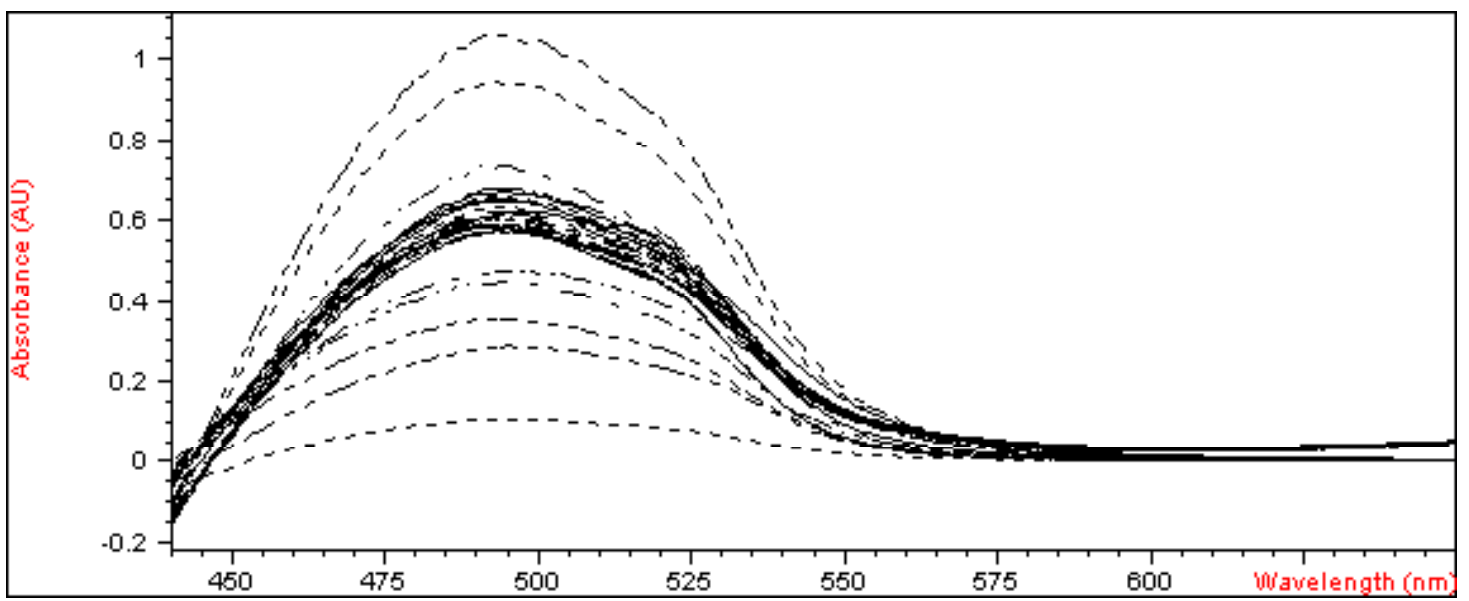

A comparison among the values of the concentrations predicted for the analytes in the actual samples and the reference values (FAAS) is presented in Table 5. A good agreement between the FBASMA and the FAAS methods was observed. 
Table 5. Metal concentrations (mg L $\left.{ }^{-1}\right)$ in the real samples by using the FBA-SMA and reference method. FBA-SMA (PLS)

Reference Method

$\begin{array}{ccccccc}\text { Samples } & \mathrm{Cu}^{2+} & \mathrm{Mn}^{2+} & \mathrm{Zn}^{2+} & \mathrm{Cu}^{2+} & \mathrm{Mn}^{2+} & \mathrm{Zn}^{2+} \\ 1 & 0.07 & 0.05 & 0.51 & 0.06 & 0.06 & 0.50 \\ 1.1 & 0.04 & 0.06 & 0.56 & 0.06 & 0.06 & 0.50 \\ 2 & 0.06 & 0.05 & 0.49 & 0.05 & 0.05 & 0.46 \\ 2.1 & 0.06 & 0.04 & 0.47 & 0.05 & 0.05 & 0.46 \\ 3 & 0.04 & 0.05 & 0.49 & 0.05 & 0.05 & 0.46 \\ 3.1 & 0.04 & 0.05 & 0.46 & 0.05 & 0.05 & 0.46 \\ 4 & 0.04 & 0.05 & 0.50 & 0.05 & 0.05 & 0.46 \\ 4.1 & 0.09 & 0.05 & 0.48 & 0.05 & 0.05 & 0.46 \\ 5 & 0.04 & 0.05 & 0.48 & 0.05 & 0.05 & 0.47 \\ 5.1 & 0.03 & 0.05 & 0.48 & 0.05 & 0.05 & 0.47 \\ 6 & 0.09 & 0.05 & 0.48 & 0.05 & 0.05 & 0.46 \\ 6.1 & 0.04 & 0.05 & 0.44 & 0.05 & 0.05 & 0.46\end{array}$

To accomplish the analyses of the actual samples after the calibration stage, the time configurations for valves switching were: $1.2 \mathrm{~s}$ for sample, $1.0 \mathrm{~s}$ for PAR reagent and $37.8 \mathrm{~s}$ for buffer solution. The homogenization time of the mixture was always $10.0 \mathrm{~s}$ and the time necessary to the mixture reach the detector was $15.0 \mathrm{~s}$. The measurements of the analytic signals have requested a time of $5.0 \mathrm{~s}$. The total time required by FBASMA to obtain the analytical signals was about 190 s, providing a sample throughput of approximately $19 \mathrm{~h}^{-1}$. The time spent to carry out the cleaning step (about $120 \mathrm{~s}$ ) and the multivariate calibration calculations were not considered in this evaluation.

\section{CONCLUSIONS}

An automatic system for simultaneous multicomponent analysis by UV-VIS spectrophotometry was developed. Using FBA-SMA and multivariate calibration analysis was possible determine simultaneously $\mathrm{Cu}^{2+}, \mathrm{Mn}^{2+}$ and $\mathrm{Zn}^{2+}$ in real samples of pharmaceutical formulations was possible.

As well as other flow-batch systems, the FBA-SMA presents the advantage of the flexibility in the preparation of the calibration and test mixtures. The time necessary for preparation and measurement of the standard mixtures is about four hours, while the manual preparation consumes at least 24 hours. Allied to analytical velocity, other characteristics of the FBA-SMA are also advantageous such as low reagent and sample consumption and good accuracy. Besides, in comparison with the reference method, it is verified that, applying the FBA-SMA it is possible to carry out a simultaneous multicomponent determination using a single spectrum per sample, while in the reference method, one analyte is determined at once increasing the time and costs for analysis. Still attempting to the analytical costs, the price of the instrument used is very smaller than the equipments used in other methodologies that employs MAS as plasma emission and ray-X fluorescence spectrometers, much less accessible to most of the research laboratories and even to most of the industrial laboratories. 


\section{Acknowledgements}

The authors are grateful to the research fellowships granted by the Brazilian agencies CNPq and CAPES.

Received August 182008

Accepted October 132009

\section{REFERENCES}

[1] I. Varga, A. von Bohlen, R. Klockenkämper, G. Záray, Microchemical Journal, 67 (2000) 265.

[2] Z. Hartyáni, E. Dávid, S. Szabó, V. Szilágyi, T. Horváth, Á. Hargitai Tóth, Microchemical Journal, 67 (2000) 195.

[3] C. Jiang, F. He, Spectrochim. Acta 59A (2003) 1321.

[4] H. Sun, R. Suo, Anal. Chim. Acta, 509 (2004) 71.

[5] H.C. Mehra, W. T. Frankenberger, Talanta, 36 (1989) 889.

[6] A. M. Garcia Rodriguez, A. Garcia de Torres, J. M. Cano Pavon, C. Bosch Ojeda, Talanta, 47 (1998) 463.

[7] H. A. Dantas Filho, E. S. O. N. de Sousa, V. Visani, S. R. R. C de Barros, T. C. B. Saldanha, M. C. U. Araújo, R. K. H. Galvão, J. Braz. Chem. Soc. 16 (2005) 58.

[8] Z. Marczenko, Spectrophotometric Determination of Elements, Sussex: Ellis Horwood, 1976. 643p.

[9] R G. Anderson, R. Nickless, Analyst, 92 (1967) 207.

[10] R G. Anderson, R. Nickless, Talanta, 14 (1967) 1221.

[11] M. A. Sharaf, D.L. Illman, B.R. Kowalski, Chemometrics, New York, Wiley, p.332, 1986.

[12] H. Martens, T. Naes, "Multivariate Calibration", London: Wiley, 1993. 419p.

[13] W.G. Glen, W.J. Dunn III, D. R. Scott, Tetr. Comp. Method., 2 (1989) 349.

[14] S. Wold, C. Albano, W.J. Dunn Iii, K. Esbensen, S. Hellberg, E. Johansson, M. Sjostrom, "Food Research and Data Analysis", London: H. Martens and H. Russwurn Jr., 1983. (Applied Science).

[15] R.R. Meglen, J. Chemom., 5 (1991) 163.

[16] P. Geladi, B.R. Kowalski, Anal. Chim. Acta, 185 (1986) 1.

[17] K. B. Beebe, B. R. Kowalski, Anal. Chem., 59 (1987) 1007.

[18] E. V. Thomas, D.M. Haaland, Anal. Chem., 62 (1990) 1091.

[19] T. Khayamian, A.A. Ensafi, B. Hemmateenejad, Talanta, 49 (1999) 587.

[20] B. J. J. Nevado, J. R. Flores, M. J. V. Llerena, N. R. Fariñas, Talanta, 48, (1999) 895.

[21] M. L. Luis, J. M. G. Fraga, F. Jiménez, A. I. Jiménez, J. J. Arias, Talanta, 53 (2001) 761.
[22] H. C. Goicoechea, A. C. Olivieri, A. M. Peña, Anal. Chim. Acta, 384 (1999) 95.

[23] M. S. Collado, V. E. Mantovani, H. C. Goicoechea, A. C. Olivieri, Talanta, 52 (2000) 909.

[24] M. S. Boeris, J. M. Luco, R. A. Olsina, J. of Pharm. and Biom. Anal., 24 (2000) 259.

[25] R. S. Honorato, M. C. U. Araújo, R. A. C. Lima, E. A. G. Zagatto, R. A. S. Lapa, J. L. F. Costa Lima, Anal. Chim. Acta, 396 (1999) 91.

[26] R. S. Honorato, J. M. T. Carneiro, E. A. G. Zagatto, Anal. Chim. Acta, 441 (2001) 309.

[27] R. S. Honorato, J. M. T. Carneiro, E. A. G. Zagatto, Fresenius J. Anal. Chem., 368 (2000) 496.

[28] L. F. Almeida, V. L. Martins, E. C. Silva, P. N. T. Moreira, M. C. U. Araújo, J. Braz. Chem. Soc. 14 (2003) 249.

[29] L. F. Almeida, V. L. Martins, E. C. Silva, P. N. T. Moreira, M. C. U. Araújo, Anal. Chim. Acta, 486 (2003) 143.

[30] R. A. C. Lima, S. R. B. Santos, R. S. Costa, G. P. S. Marcone, R. S. Honorato, V. B. Nascimento, M. C. U. Araújo, Anal. Chim. Acta, 518 (2004) 25.

[31] J. E. da Silva, F. A. da Silva, M. F. Pimentel, R. S. Honorato, V. L. da Silva, B. S. M. Montenegro, A. N. Araújo, Talanta, 70 (2006) 522.

[32] E. P. Medeiros, E. C. L. Nascimento, A. C. D. Medeiros, J. G. V. Neto, E. C. da Silva, M. C. U. Araújo, Anal. Chim. Acta, 511 (2004) 113.

[33] L. F. Almeida, M. G. R. Vale, M. B. Dessuy, M. M. Silva, R. S. Lima, V. B. Santos, P. H. D. Diniz, M. C. U. Araújo, Talanta, 73 (2007) 906.

[34] M. Grünhut, M. E. Centurión, W. D. Fragoso, L. F. Almeida, M. C. U. Araújo, B. S. F. Band, Talanta, 75 (2008) 950.

[35] C Pasquini, E. V. Aquino, M. V. Rebouças, F. B. Gonzaga, Anal. Chim. Acta, 600 (2007) 84

[36] A. J. C. Garcia and B. F. Reis, J. Autom. Meth. and Manag. Chem., 1 (2006) 1

[37] E. V. Aquino, J. J. R. Rohwedder, C. Pasquini, Talanta, 71 (2007) 1288

[38] T. Morita, R.M.V. Assumpção, Manual de Soluções, Reagentes \& Solventes, $2^{\mathrm{a}}$ Edição, São Paulo, Editora Edgard Blucher, p.381, 1972.

[39] Unscrambler User's Guide, Versão 6.1, CAMO A/S, Trondheim, 1993.

[40] T. C. B. Saldanha, M. C. U. Araújo, B. B. Neto, H. C. Chame, Anal. Letters, 33 (2000) 1187.

[41] J. D. Lee, Química Inorgânica: Um novo texto conciso,

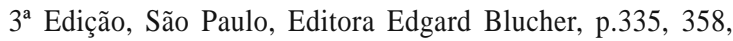
374, 382, 1980. 